\title{
Development of CaO/PVA Catalyst from Fish Bone for Biodiesel Production
}

\author{
Sarina Sulaiman*, Nor Fatin Abdul Jamaludin, Nassereldeen Ahmed Kabbashi \\ Department of Biotechnology Engineering, Kulliyyah of Engineering, International Islamic University \\ Malaysia (IIUM), Jalan Gombak, 53100 Kuala Lumpur, Malaysia
}

Received: 20 th January 2018; Revised: 28th September 2018; Accepted: 30 th September 2018; Available online: 25th January 2019; Published regularly: April 2019

\begin{abstract}
In this study, calcium oxide were synthesized from fish bone waste and the optimum condition: catalyst amount, reactor temperature, and methanol to oil ratio (molar) for biodiesel production were studied. The calcium oxide $(\mathrm{CaO})$ derived from fish bone wastes was then supported on polyvinyl alcohol (PVA) to easily separate the catalyst and biodiesel. Fish bone were dried in oven at $70{ }^{\circ} \mathrm{C}$ for 24 $\mathrm{h}$ before calcination process at $900{ }^{\circ} \mathrm{C}$ for $4 \mathrm{~h}$. The biodiesel yield was studied by varying three parameters, namely methanol to oil ratio (molar) (6:1 - 20:1), amount of catalyst (1-10 wt\%) and temperature $\left(55-65^{\circ} \mathrm{C}\right)$. The highest fatty acid methyl ester (FAME) yield obtained from this study was at $80.40 \%$ with catalyst amount of $10 \mathrm{wt} \%$, methanol to oil ratio (molar) of 20:1, and temperature of 65 ${ }^{\circ}$ C. Copyright (C) 2019 BCREC Group. All rights reserved
\end{abstract}

Keywords: Calcium Oxide; Fish Bone; Calcination; Biodiesel; PVA; Transesterification

How to Cite: Sulaiman, S., Jamaludin, N.F.A., Kabbashi, N.A. (2019). Development of CaO/PVA Catalyst from Fish Bone for Biodiesel Production. Bulletin of Chemical Reaction Engineering \& Catalysis, 14 (1): 153-157 (doi:10.9767/bcrec.14.1.3327.153-157)

Permalink/DOI: https://doi.org/10.9767/bcrec.14.1.3327.153-157

\section{Introduction}

Increase in demand of petroleum-based fuel, global warming and higher petroleum prices leads on the search of alternative and renewable sources. Researcher found that biodiesel is the best alternative source to substitute conventional fuel since it has almost similar properties of combustion with petroleum diesel. Besides that, biodiesel is more environmental friendly compared to automotive fuel because it emits less amount of sulphur dioxide than conventional fuel.

Biodiesel can be produced from animal or vegetable oil is via transesterification or alco-

\footnotetext{
* Corresponding Author.

E-mail: sarina@iium.edu.my (S. Sulaiman)
}

holysis. Animal fats or vegetable oil is reacted with alcohol such as methanol or ethanol with the presence of catalyst to form ester (biodiesel) and glycerol. The main function of catalyst in transesterification is to increase the reaction rate and yield of product [1]. Biocatalyst, heterogeneous and homogeneous catalysts are commonly used in biodiesel production. Sodium hydroxide $(\mathrm{NaOH})$, hydrochloric acid $(\mathrm{HCl})$, and potassium hydroxide $(\mathrm{KOH})$ are example of homogenous catalysts. These type of catalyst provides shorter reaction time and able to produce high FAME yield at mild conditions [2]. Unfortunately, homogenous catalysts have some drawbacks, such as: produces large amount of wastewater and it cannot be reused which leads to high production cost [3]. Heterogeneous catalyst offers many advantages that can overcome 
problems of homogenous catalyst. At the end of the transesterification process, the separation of heterogeneous catalyst is easier compared to homogeneous catalyst. Besides that, heterogeneous catalyst can be reused several times, which reduces the production cost. Heterogeneous catalyst can be produced from restaurant wastes like fish bone, eggshell, chicken bone, and crab shell. Usually, these wastes are disposed and rich of calcium carbonate. This proves that this wastes can be a good substitute as catalyst in biodiesel production [4].

Naturally, bones contains of $70 \%$ of inorganic minerals, $20 \%$ of organic matter and 10 $\%$ water while fish bone contains 60 to $70 \%$ of inorganic substances mainly comprised of hydroxyapatite and calcium phosphate [5]. Fish bones contains high mineral contents which is about $34-36 \%$ of calcium [3]. Like others raw materials, fish bone needs to undergo calcination process in order to produce $\mathrm{CaO}$. Biodiesel/FAME yield of $97.73 \%$ was obtained at 2 $\mathrm{h}$ from reaction of methanol and soybean oil when $\mathrm{CaO}$ derived from fish bone (1.01 wt\%) catalyst was used [6]. This indicates that the restaurant or household wastes can be utilized to produce catalyst for biodiesel production.

This study aims to develop a heterogeneous catalyst from fish bone waste supported with polyvinyl alcohol (PVA) to ease the biodiesel and catalyst separation and to determine the optimum condition, such as: catalyst amount, reaction temperature, and methanol to oil ratio (molar). Heterogeneous catalyst has many advantages including does not produce wastewater, being reusable and can reduces the overall cost of production.

\section{Materials and Methods}

\subsection{Material Preparation}

Fish bone wastes (any type) were collected from cafetaria in International Islamic University Malaysia (IIUM) Gombak. Then, fish bones were dried in the oven at $70{ }^{\circ} \mathrm{C}$ for 24 hours in order to remove the water and excessive moisture. Fish bones were grounded and crushed by using mortar until they turned into powder. Then, powdered fish bones were calcined using muffle furnace at $900{ }^{\circ} \mathrm{C}$ for $4 \mathrm{~h}$. The calcined sample was kept in desiccator.

\subsection{Preparation of $\mathrm{CaO} / \mathrm{PVA}$}

Two grams of polyvinyl alcohol powder were added slowly into $50 \mathrm{~mL}$ of water to avoid the formation of lumps. The solution was heated at $90{ }^{\circ} \mathrm{C}$ about 2 hours under continuous stirring at $200 \mathrm{rpm}$ until aqueous polyvinyl alcohol was obtained. After aqueous polyvinyl was obtained, the calcined fish bones were added into the aqueous polyvinyl alcohol. Then, the solution was allowed to dry at room temperature. Sample of $1 \times 1 \mathrm{~cm}$ was prepared.

\subsection{Transesterification Process}

Palm oil, methanol, and catalyst were poured into the shake flask and were placed in the incubator shaker for 3 hours at agitation speed of $200 \mathrm{rpm}$. After 3 hours, catalyst was filtered and the solution was left overnight in the oven at $60{ }^{\circ} \mathrm{C}$ to remove the excess methanol. The resultant mixture was left in the separatory funnel for separation process. There were two layers formed; upper layer was biodiesel and bottom layer was glycerol. The bottom layers were discarded to obtain the biodiesel. The biodiesel composition was determined using Agilent 6890 GC. $1 \mathrm{~mL}$ of sample was diluted with $3.9 \mathrm{~mL} \mathrm{n}$-hexane and $1 \mathrm{~mL}$ of sample was injected into GC and process. The yield of fatty acid methyl ester (FAME) was calculated by using Equation (1):

FAME Yield $(\%)=\frac{\text { weight of acid methylester }(g)}{\text { weight of oil used }(g)} \times 100$

\subsection{Experimental Design}

The optimization of biodiesel production was performed using Design Expert 6.0.7 (StatEase Inc., USA). Factorial Central Composite Design (FCCD) was used to optimize the biodiesel yield with three central points and 17 runs. Table 1 indicates the experimental design for optimization. The reaction time was kept constant at 3 hours.

\subsection{Reusability}

The reusability of the catalyst was determined by repeating transesterification cycle. After 4 hours of the transesterification reaction, the catalysts were separated from the mixture and were washed with double distilled water. Then, it was washed with acetone and finally it was dried in an oven at $50{ }^{\circ} \mathrm{C}[7]$.

\section{Results and Discussion}

\subsection{Optimization of Transesterification Process}

The optimization for the biodiesel yield was performed using Factorial Central Composite Design (Design Expert 6.0.8), with three central points and 17 of total runs. Analysis of 
variance (ANOVA) represents the interaction of variables with the response and effect of individual parameters. Thus, the ANOVA was performed to study the significance and fitness of the model. The final equation in terms of coded factors:

FAME Yield $=+68.82+0.47 A+6.46 B+0.95 C$ $+3.20 A^{2}-1.40 B^{2}-0.80 C^{2}+1.07 A B+2.06 A C$ $+0.47 B C$

Where $A, B$, and $C$ represent methanol to oil ratio, amount of catalyst (wt\%), and temperature $\left({ }^{\circ} \mathrm{C}\right)$, respectively. The positive signs indicate synergies effect while the negative signs justified the antagonistic effects. From the Equation (1), $A, B, C, A^{2}, A B, A C$, and $B C$, were positive which were crucial in increasing the FAME yield while $B^{2}$ and $C^{2}$ were negative.

Table 2 shows the ANOVA for respond surface quadratic model. The model implied that it was significant, since the model $F$-value was 20.40. The model was considered as significant due to the value of Prob $>F$ less than 0.05. The significance of each regression coefficient and the interaction effect of each cross product can be determined through probability error or known as $p$-value [8].
The $B, A^{2}$, and $A C$ were significant model terms for this case. The model terms were considered not significant if the values greater than 0.1000. Lack of fit (2.35) showed not significant relative to the pure error. There was a $32.48 \%$ chance that a lack of fit $F$-value this large could occur due to noise.

The $R$-squared for this model was 0.9633 , which indicated that $96.33 \%$ of total variation in FAME yield was attributed to the experimental variables was studied. The "Pred $R$-squared" for this model was 0.7546 and it showed that this Pred $R$-squared value was in reasonable agreement with the value of $\operatorname{Adj} R$ Squared which was 0.9160 . Signal to noise ratio showed 16.63 which is greater than 4 and this model could be used to navigate the design space.

Figure 1 shows the effect of amounts of catalyst and methanol to oil ratio (molar) used in transesterification process. The biodiesel yield of $78.63 \%$ was obtained with catalyst amount of $10 \mathrm{wt} \%$, temperature of $60{ }^{\circ} \mathrm{C}$ and methanol to oil ratiol of 20:1. The yield decreased slightly when methanol to oil ratio (molar) was decreased. This might occur due to the excess of methanol which increases the concentration of glycerol and led to the difficulty in separation process [9]. Further

Table 1. Experimental design for optimization and results

\begin{tabular}{ccccc}
\hline Run & $\begin{array}{c}\text { Amount of catalyst } \\
(\text { wt } \%)\end{array}$ & Methanol:oil ratio & Temperature $\left({ }^{\circ} \mathrm{C}\right)$ & $\begin{array}{c}\text { FAME yield } \\
(\%)\end{array}$ \\
\hline 1 & 1.0 & 6 & 65 & 62.70 \\
2 & 10.0 & 20 & 55 & 73.75 \\
3 & 5.5 & 13 & 60 & 68.00 \\
4 & 5.5 & 20 & 60 & 75.40 \\
5 & 5.5 & 13 & 55 & 66.20 \\
6 & 10.0 & 6 & 55 & 60.50 \\
7 & 1.0 & 13 & 60 & 70.60 \\
8 & 10.0 & 13 & 60 & 74.50 \\
9 & 5.5 & 6 & 60 & 60.50 \\
10 & 5.5 & 13 & 65 & 70.90 \\
11 & 1.0 & 20 & 55 & 75.90 \\
12 & 5.5 & 13 & 60 & 69.35 \\
13 & 5.5 & 13 & 60 & 67.00 \\
14 & 1.0 & 6 & 55 & 66.15 \\
15 & 1.0 & 20 & 65 & 73.55 \\
16 & 10.0 & 20 & 65 & 80.40 \\
17 & 10.0 & 6 & 65 & 64.50 \\
\hline
\end{tabular}


increase in methanol to oil ratio (molar) has no significant impact on the biodiesel yield.

Figure 2 shows the relationship between of catalyst and temperature. The higest yield of biodiesel was obtained at $74.70 \%$ when other parameters was fixed at catalyst amount of 10 wt\% , methanol to oil ratio (molar) of 13:1, and temperature of $65{ }^{\circ} \mathrm{C}$. The lowest yield of

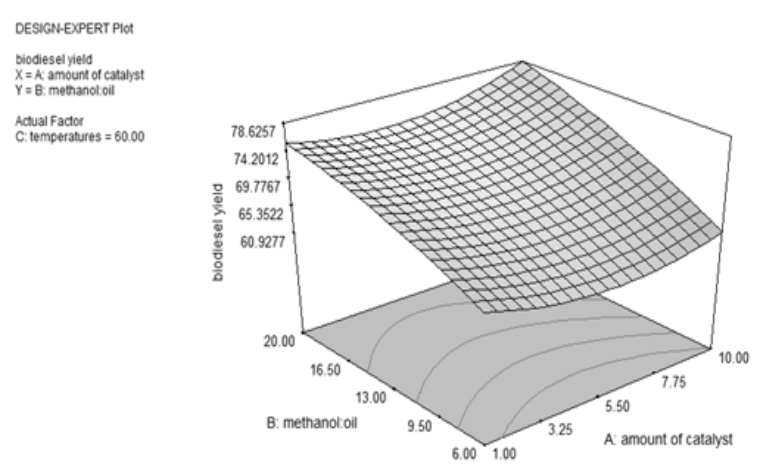

Figure 1. Surface model for interaction of amounts of catalyst and methanol:oil molar ratio

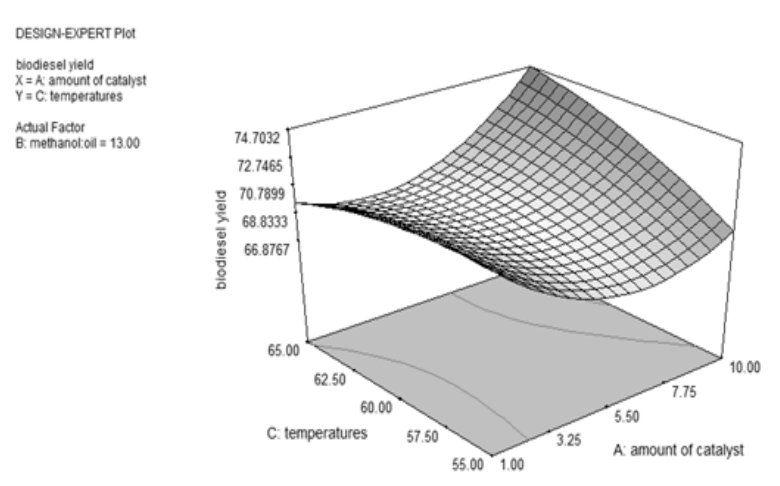

Figure 2. Surface model for interaction of catalyst and temperature biodiesel was donated by transesterification with catalyst amount of $5.5 \mathrm{wt} \%$ and reaction temperature of $55{ }^{\circ} \mathrm{C}$. More active sites available in the reaction when the catalyst amount was added and this led to the increasing of fatty acid methyl ester production [10].

Three-dimensional response surface in Figure 3 showed the effect of methanol to oil ratio (molar) with temperature in conversion of oil to biodiesel process. Figure 3 shows the yield increases when methanol to oil ratio (molar) and temperature had been increased with catalyst amount of $5.5 \mathrm{wt} \%$. The biodiesel yield increased significantly up to $74.52 \%$ at temperature between 55 to $65{ }^{\circ} \mathrm{C}$ with methanol to oil ratio (molar) of 20:1 while the lowest biodiesel yield which is about $59.67 \%$ was donated by methanol to oil ratio (molar) of 6:1 with temperature at $55{ }^{\circ} \mathrm{C}$. Further increase of temperature led to the decrease of biodiesel produced due to the evaporation of methanol [11].

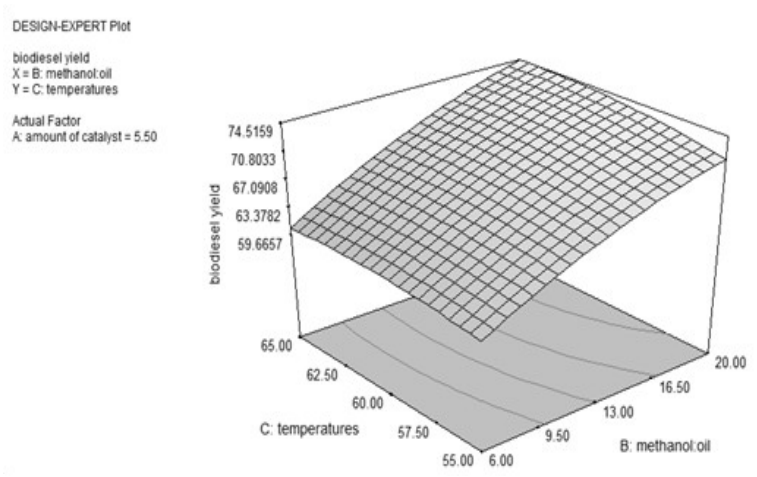

Figure 3. Surface Model for interaction of methanol:oil molar ratio

Table 2. ANOVA results

\begin{tabular}{lcccccc}
\hline Source & Sum of squares & DF & Mean square & $F$-value & Prob $>F$ & \\
\hline Model & 501.80 & 9 & 55.76 & 20.40 & 0.0003 & Significant \\
$\mathrm{A}$ & 2.26 & 1 & 2.26 & 0.83 & 0.3938 & \\
$\mathrm{~B}$ & 417.96 & 1 & 417.96 & 152.90 & $<0.0001$ & \\
$\mathrm{C}$ & 9.12 & 1 & 9.12 & 3.34 & 0.1105 & \\
$\mathrm{~A}^{2}$ & 27.38 & 1 & 27.38 & 10.02 & 0.0158 & \\
$\mathrm{~B}^{2}$ & 5.28 & 1 & 5.28 & 1.93 & 0.2074 & \\
$\mathrm{C}^{2}$ & 1.73 & 1 & 1.73 & 0.63 & 0.4526 & \\
$\mathrm{AB}$ & 9.14 & 1 & 9.14 & 3.34 & 0.1102 & \\
$\mathrm{AC}$ & 33.83 & 1 & 33.83 & 12.37 & 0.0098 & \\
$\mathrm{BC}$ & 1.76 & 1 & 1.76 & 0.64 & 0.4490 & \\
\hline Residual & 19.13 & 7 & 2.73 & & & \\
Lack of fit & 16.35 & 5 & 3.27 & 2.35 & 0.3248 & Not significant \\
Pure error & 2.78 & 2 & 1.39 & & & \\
Cor total & 520.94 & 16 & & & & \\
\hline
\end{tabular}


Sulaiman et al. [12] reported that the highest yield of $86 \%$ was achieved using $\mathrm{CaO}$ derived from fish bone. In another study, it is mentioned that the best catalytic activity was achieved with maximum biodiesel yield of $93 \%$ in the transesterification of waste cooking oil at $4 \%(\mathrm{w} / \mathrm{v})$ of catalyst loading by adding hexane as a cosolvent [13]. This proves that the fish bone can be utilized as catalyst and to enhance the yield, some modification is needed.

\subsection{Model Fitting Validation}

The percentage error of this model could be determined by performing the validation. The solution suggested that catalyst amount of 10 wt\% with methanol to oil ratio (molar) of $20: 1$ and temperature at $65{ }^{\circ} \mathrm{C}$ produced $81.30 \%$ of biodiesel. The biodiesel yield obtained from this solution was $80.40 \%$. Then, the percentage error calculated was $1.11 \%$.

\subsection{Reusability Test}

The reusability test showed that the yield was around $\sim 80.4 \%$ when it was used up to 5 times with fixed reaction parameters; methanol to oil ratio (molar) of 20:1, catalyst amount of $10 \mathrm{wt} \%$ and temperature at $65^{\circ} \mathrm{C}$. Beyond that, the yield showed a drop $\sim 5 \%$. The results concluded that the catalyst could be reused up to 5 times with a slight difference in the yield.

\section{Conclusion}

The highest biodiesel yield of $80.40 \%$ was obtained at the optimum conditions of methanol to oil ratio (molar) of 20:1, catalyst amount of $10 \mathrm{wt} \%$, and temperature at $65{ }^{\circ} \mathrm{C}$. Fish bone wastes demonstrates high potential to be used as a catalyst for biodiesel production by transesterification of palm oil, because it contains calcium oxide. Furthermore, the separation between catalyst and biodiesel were easy.

\section{References}

[1] Ma, F., Hanna, M.A. (1999). Biodiesel Production: A Review. Bioresource Technology, 70(1): $1-15$.

[2] Niju, S., Meera, K., Begum, S., Anantharaman, N. (2014). Modification of Egg Shell and Its Application in Biodiesel Production. Journal of Saudi Chemical Society, 18(5): 702-706.
[3] Viriya-Empikul, N., Krasae, P., Puttasawat, B., Yoosuk, B., Chollacoop, N., Faungnawakij, K. (2010). Waste Shells of Mollusk and Egg as Biodiesel Production Catalysts. Bioresource Technology, 101(10): 3765-3767.

[4] Wei, Z., Xu, C., Li, B. (2009). Application of Waste Eggshell as Low-Cost Solid Catalyst for Biodiesel Production. Bioresource Technology, 100(11): 2883-2885.

[5] Liyanage, C.D., Pieris, M. (2015). A PhysicoChemical Analysis of Coconut Shell Powder. Procedia Chemistry, 16: 222-228.

[6] Sulaiman, S., Ruslan, N. (2017). A Heterogeneous Catalyst from a Mixture of Coconut Waste and Eggshells for Biodiesel Production. Energy Sources, Part A: Recovery, Utilization, and Environmental Effects, 39(2): 154159

[7] Obadiah, A., Swaroopa, G.A., Kumar, S.V., Jeganathan, K.R., Ramasubbu, A. (2012). Biodiesel Production from Palm Oil Using Calcined Waste Animal Bone as Catalyst. Bioresource Technology, 116(0): 512-516.

[8] Chen, K.-T., Wang, J.-X., Dai, Y.-M., Wang, P.-H., Liou, C.-Y., Nien, C.-W., Wu, J.-S., Chen, C.-C. (2013). Rice Husk Ash as a Catalyst Precursor for Biodiesel Production. Journal of the Taiwan Institute of Chemical Engineers, 44(4): 622-629.

[9] Musa, I.A. (2016). The Effects of Alcohol to Oil Molar Ratios and the Type of Alcohol on Biodiesel Production Using Transesterification Process. Egyptian Journal of Petroleum, 25(1): 21-31.

[10] Gashaw, A., Getachew, T., Teshita, A. (2015). A Review on Biodiesel Production as Alternative Fuel. J. For. Prod. Ind., 4: 80-85.

[11] Jagadale, S., Jugulkar, L. (2012). Review of Various Reaction Parameters and other Factors Affecting on Production of Chicken Fat Based Biodiesel. International Journal of Modern Engineering Research, 2(2): 407-411.

[12] Sulaiman, S., Amin, M. (2016). Fish BoneCatalyzed Methanolysis of Waste Cooking Oil. Bulletin of Chemical Reaction Engineering \& Catalysis, 11 (2): 245-249

[13] Widiarti, N., Wijianto, W., Wijayati, N., Harjito, H., Kusuma, S.B.W., Prasetyoko, D., Suprapto, S. (2017). Catalytic Activity of Calcium Oxide From Fishbone Waste in Waste Cooking Oil Transesterification Process. Jurnal Bahan Alam Terbarukan, 6(2): 97-106.

Selected and Revised Papers from The $4^{\text {th }}$ International Conference of Chemical Engineering \& Industrial Biotechnology (ICCEIB 2018) (http://icceib.ump.edu.my/index.php/en/) (Universiti Malaysia Pahang, by 1 1t_2 ${ }^{\text {nd }}$ August 2018) after Peer-reviewed by Scientific Committee of ICCEIB 2018 and Peer-Reviewers of Bulletin of Chemical Reaction Engineering \& Catalysis 